\title{
Advanced Practice Nursing in Primary Health Care in the Spanish National Health System
}

\author{
Enfermagem Prática Avançada em atenção primária no Sistema \\ Nacional de Saúde espanhol
}

Kerstin Hämel (https://orcid.org/0000-0003-1034-2373) ${ }^{1}$

Beatriz Rosana Gonçalves de Oliveira Toso (https://orcid.org/0000-0001-7366-077X) ${ }^{2}$

Angela Casanova (https://orcid.org/0000-0002-7888-9490) ${ }^{3}$

Ligia Giovanella (https://orcid.org/0000-0002-6522-545X) ${ }^{3}$

${ }^{1}$ School of Public Health, Bielefeld University. Universitätsstraße 25, D-33615 Bielefeld.

Alemanha.kerstin.haemel@ uni-bielefeld.de

${ }^{2}$ Centro de Ciências Biológicas e da Saúde, Universidade Estadual do Oeste do Paraná. Cascavel PR Brasil.

${ }^{3}$ Escola Nacional de Saúde Pública, Fundação Oswaldo Cruz. Rio de Janeiro RJ Brasil.

\begin{abstract}
The primary health care in the Spanish National Health System is organised in health centres with multi-professional teams, composed of doctors and nurses specialised in family and community health, in addition to other professionals. This article analyses the role of primary health care nurses in the Spanish National Health System. In the last decade, new concepts of task sharing between doctors and nurses as well as advanced nursing roles have been evolved in the health centres that focus on improving care for chronically ill patients and access to primary care. With shared responsibility, nurses are responsible for chronic patients in stable conditions, health prevention and promotion. The scaling up of advanced nursing tasks is limited by uncertainties of roles, disparities between states, and legislations that do not cover the full extent of advanced nursing tasks. The case study of Spain indicates that a strong multi-professional model of primary health care teams is a crucial basis for the evolvement of advanced nursing practice and its acceptance in daily routines. However, advantageous education structures and legislations are needed to allow nurses to develop their contribution in the full potential.

Key words Primary health care, General practice, Provision of health care, Community health, Advanced practice nursing
\end{abstract}

Resumo A atenção primária no Sistema Nacional de Saúde espanhol é prestada em centros de saúde públicos, com equipe composta de médicos e enfermeiros especialistas em família e comunidade, além de outros profissionais. Neste artigo, se analisa a atuação do enfermeiro na atenção primária no Serviço Nacional de Saúde espanhol. Na última década, buscando efetividade no manejo de condições crônicas e melhor acesso à atenção, novos modelos de ações compartilhadas entre médicos e enfermeiros, bem como práticas avançadas de enfermagem foram desenvolvidas. Atualmente, com responsabilidades compartilhadas, enfermeiros são responsáveis por pacientes com condições crônicas estáveis, além de ações de prevenção e promoção. Não obstante, a prática avançada em enfermagem é limitada por indefinição de funções, disparidade de atuação entre Estados e legislação insuficiente, que não abarca o potencial desta prática. O caso da Espanha indica que um modelo de atenção multiprofissional forte na atenção primária é crucial para o desenvolvimento da enfermagem de prática avançada. Entretanto, promover formação e legislação adequada à essa prática é necessário, para que os enfermeiros contribuam com todo o seu potencial na atenção primária à saúde.

Palavras-chave atenção primária a saúde, unidades de atenção primária, prestação de serviços de saúde, saúde da comunidade, prática avançada de enfermagem. 


\section{Introduction}

The Spanish National Health System (NHS) provides universal coverage and free access to health care for the population in Spain on a tax-based funding. Its establishment in the year 1986 was accompanied by the goal to transform health care delivery from a hospital-driven to a primary health care centred model ${ }^{1,2}$. Today, primary health care (PHC) centres are building a dense network throughout the country. They are organised around a multi-professional team, providing preventive, curative and rehabilitative care, and, moreover, assuming a gatekeeping function to navigate the patient through the health system ${ }^{3-5}$. The primary health care teams are composed mainly by physicians and nurses, both specialised in the field of family and community medicine ${ }^{5,6}$.

Today, the PHC in Spain is one of the strongest in Europe ${ }^{7,8}$. Accessibility, continuity of care and coordination are guaranteed at a high level; the primary care services provided are comprehensive. Compared to other countries in Europe, the PHC in Spain is supported by beneficial governance, sufficient economic conditions, and qualification of the workforce for primary care ${ }^{5,7,8}$. However, the Spanish NHS is decentralised, each of the 17 states (Autonomous Communities, CCAA), having developed own legislation and plans with some differences between CCAA Health Services.

Recently, the NHS in Spain has been challenged in many ways. Budgets for health care have fallen as a result of the economic crisis after $2008^{9}$ and the share of primary care spending on the overall public expenditure for health care has decreased $^{6}$. On the other hand, there have been a change and increase in the need for primary health care as a result of accelerating demographic ageing and an increase in chronic diseases among the Spanish population ${ }^{10}$. In order to deal with these and related challenges, a further development of primary care is being discussed presently, which aims at the organisational integration of primary care and secondary care ${ }^{6}$, new concepts of team cooperation in the health centres as well as the testing of new task sharing between the health professions in the centres ${ }^{11}$. The focus here has been placed particularly on possibilities for further developing the tasks and roles of nurses in primary care. This follows the growing evidence that nurses can make a significant contribution to better meet the new and complex health needs of the population ${ }^{12,13}$.

Spain does not stand alone in this development. Internationally, there are many initiatives to expand the functions of nursing, giving nurses greater autonomy in providing patient care - by assigning new tasks, e.g. preventive health care, to PHC nurses and also by task shifting from doctors to nurses ${ }^{14}$. A recent Cochrane review reports that task shifting from doctors to nurses is one strategy used to improve access, efficiency and quality of primary health care $\mathrm{e}^{15}$.

The review investigated what impact nurses working as substitutes for primary care doctors had on patient outcomes, processes of care, and utilisation. It concludes that, compared with doctors, qualified nurses probably provide equal or possibly even better quality of care and health outcomes. With nurses, levels of patient satisfaction are likely to be higher, consultations to last longer and return visits to be attended slightly more frequently than with doctors ${ }^{15}$. However, there still lacks research on the specific contribution of nurses to the PHC in Spain and its prospects.

The goal of this article is to describe and analyse the role of PHC nurses in the Spanish National Health System (NHS). Below, we will begin with an outline of the NHS organisation. Then, a closer look at the PHC organisation will be taken, and nurses' roles, nursing tasks and interprofessional collaboration in the PHC teams will be discussed. Lastly, progress made in Advanced Practice Nursing study programs and implementation of newly the established profession will be evaluated, and developing prospects and constraints discussed.

\section{The National Health System in Spain}

Spain is a country of high socioeconomic level with 46.5 million inhabitants and good health results. Some of Spain's social, economic and health indicators are presented in Table 1.

The Spanish National Health System (NHS) migrate from a Bismarckian model of social insurance to a Beveridgian model of National Health Service with universal access and fiscal financing ${ }^{16}$. In the process of democratisation after the dictatorship of Franco, there was a transformation of the political-territorial organisation ${ }^{17}$, where health politics were decentralized aiming at transferring health care responsibilities to the Autonomous Communities, in a process completed in 2002, reaching all CCAA, so health care in Spain was regionalised ${ }^{4}$.

The CCAA have autonomy in the budgetary management of central government financial transfers, with jurisdiction to coordinate the network of health services in their territory ${ }^{18}$. Consequently, each CCAA has created a Health 
Table 1. Selected economic, demographic and health indicators, Spain, 2017*.

\begin{tabular}{|c|c|}
\hline Indicators & Data \\
\hline \multicolumn{2}{|l|}{ Demographic } \\
\hline Total population (millions of inhabitants 2017) ${ }^{1}$ & 46,549 \\
\hline$\%$ Population 65 years and $+{ }^{1}$ & $19.0 \%$ \\
\hline Life expectancy at birth ${ }^{1}(2017)$ & 83.4 \\
\hline Male & 80.4 \\
\hline Female & 86.2 \\
\hline Infant mortality rate per 1000 live births $(2016)^{1}$ & 2.7 \\
\hline Human Development Index $(2017)^{2}$ & 0.891 \\
\hline Gini Index $(2016)^{3}$ & 0.345 \\
\hline \multicolumn{2}{|l|}{ Macroeconomic and health expenditure } \\
\hline GDP (US\$/capita) $(2018)^{3}$ & 40,846 \\
\hline Government expenditure on health as \% of GDP $(2017)^{3}$ & 6.3 \\
\hline Government expenditure on health as \% of total health expenditure (2017) ${ }^{3}$ & $70.8 \%$ \\
\hline Public Health expenditure per capita in Euros $(2016)^{3}$ & 1435.79 \\
\hline Primary care expenditure as a share of total public health expenditure $(2016)^{1}$ & $13.67 \%$ \\
\hline Secondary care expenditure as a share of total public health expenditure $(2016)^{1}$ & $64.12 \%$ \\
\hline \multicolumn{2}{|l|}{ Health resources } \\
\hline Doctors (Total) per 1.000 inhabitants $(2016)^{3}$ & 3,80 \\
\hline Nurses (Total) per 1000 inhabitants $(2016)^{3}$ & 5,50 \\
\hline Primary Care doctors per 1000 registered pop. $(2016)^{1}$ & 0.77 \\
\hline Primary Care Nurses per 1000 registered pop. $(2016)^{1}$ & 0,65 \\
\hline Specialist doctors per 1000 pop $(2016)^{1}$ & 1,90 \\
\hline Nurses in secondary care per 1000 pop $(2016)^{1}$ & 3,27 \\
\hline Public beds (2016) & $79.9 \%$ \\
\hline \multicolumn{2}{|l|}{ Accessibility } \\
\hline Waiting time for non-urgent surgical procedures $(2017)^{1}$ & 106 days \\
\hline Waiting time for medical specialist consultation. $(2017)^{1}$ & 66 days \\
\hline \multicolumn{2}{|l|}{ Health care utilisation } \\
\hline Primary care consultations per capita for registered population (GP + Paediatricians) $(2017)^{1}$ & 5.07 \\
\hline Nurses primary care consultations per capita for registered population $(2017)^{1}$ & 2.87 \\
\hline Specialist doctor consultations in NHS as a percent of the total consultations in Spain (2016) ${ }^{1}$ & $80.9 \%$ \\
\hline Hospital admissions in the NHS as share of total hospital admissions $(2016)^{1}$ & $75.9 \%$ \\
\hline
\end{tabular}

Service Department to manage health services under a regional health authority with some discrepancies between the states. This also includes the PHC introduced by a reform in 1984 that created multi-professional teams mainly composed of salaried general practitioners (GPs) and nurses who practice in full and exclusive dedication to the NHS, expanding and improving the health centres infrastructure and strengthening the function of GP as a gatekeeper ${ }^{16}$.

Resolutions and decisions on general legislation, objectives and minimum requirements for healthcare services are defined at the national level. These nationwide regulations on health care - such as primary care - are specified by de- tailed legislation and decisions of the $17 \mathrm{CCAA}^{4}$. The Interterritorial Council of the NHS is constituted to promote the cohesion inside the system with the aim of equal health rights for all Spaniards. In addition, a common service portfolio was established in the NHS, in order to provide universal health care provision with similar quality throughout the national territory ${ }^{18}$. Beyond national standards, each CCAA can provide additional services, such as different models of care for chronically ill people, and adopt distinctive management structures for health care supply ${ }^{18}$.

However, measures taken following the economic crisis of 2008 resulted in restrictions on the service basket and an increase of co-pay- 
ments for medicines 9 . Other changes in coverage rules of the NHS, including the exclusion of undocumented migrants from free access to health care, were abolished in $2018^{22}$.

Each CCAA has an "Autonomous Health Service" organised regionally and territorialised in so-called Health Areas with $\pm 250,000$ inhabitants constituted by \pm 18 Basic Zones. The Basic Health Zone (population 5,000 to 25,000) is the territorial framework for PHC established as the basis for the NHS, with direct access to the population for providing integral and continuous care. In each zone, there is a health centre that is the first contact service, with a gatekeeping function for the specialised care provided in hospital outpatient clinics or specialty centres linked to the area's public hospital of the CCAA ${ }^{16}$.

The management of the Autonomous Health Services is based on program contracts that commission objectives, care models, activities, resources, budgets and evaluation systems and indicators. The service contract is negotiated for each level of care between the Autonomous Health Service and the management of the Health Areas, and with the health facilities in its territory ${ }^{23}$. Patient flows for specialised care, innovations, technical quality, patient safety and professional development are valued in program contracts. In Table 2, characteristics of the NHS in Spain are summarised.

\section{Primary Health Care in the NHS}

To access the NHS service regularly, people must register with a PHC centre, usually in their residence zone. In the health centre, each patient has a personal GP and nurse. Patients can choose both independently but, in most cases, doctors and nurses form fixed tandems in order to assume responsibility for a common patient base $^{5,24}$. The entire population is assigned via patient lists to the PHC professionals. Each doctor is responsible for an average of 1,400 registered users. The ratio is slightly higher for the nursing staff. Differences in the patient load between the CCAAs are substantial (Table 2). The children up to 14 years old are assigned to a paediatrician with a list of 800 to 1,100 children, who, likewise, should collaborate closely with a paediatric nurse $\mathrm{e}^{25,26}$.

In the year 2017, PHC doctors conducted 5.1, PHC nurses 2.9 consultations for each patient (see Table 2). Again, the distribution of doctors and nurses across CCAAs varies, from 0.63 to 1.1 doctors, and from 0.50 to 0.88 nurses per 1,000 registered people ${ }^{6}$. The health professionals are employees of the CCAA and the PHC remuneration of doctors is based on salary plus per capita complement per registered user, adjusted according to age?.

The GP or paediatrician has the gatekeeping function to refer the patient to the specialised care. Some CCAA seek to promote the integration of management, services and multi-professional teams, e.g. through the formation of joint commissions for primary and specialised care, Integrated Health Care organisations, and other models ${ }^{27}$. Interconsultation strategies also have been adopted between primary and secondary care, with an emphasis on clinic management, transformed into objectives in program contracts established between care directorates and services managemen ${ }^{23}$.

The primary health care infrastructure of the NHS encompasses a network of 3,039 health centres and 10,055 local health offices (consultorios locales $)^{28}$. The vast majority of the PHC centres are managed and owned by the 17 CCAA, e.g. the Basque Public Health Service "Osakidetza" or the Andalusian Health Service "Servicio Andaluz de Salud". Health centres are established based on the requirement that all citizens should be able to reach a health centre within 15 minutes (30 at maximum $)^{4}$. Following regional health planning traditions services offered by the health centres are adjusted to the health needs of the targeted territorial population ${ }^{5}$.

In order to provide PHC services to rural communities, many centres provide local health offices as satellite contact points ${ }^{8}$. Hereby, health care centres benefit from active support of the municipality that can provide rooms and spaces for these facilities ${ }^{11}$. Head of the health centres are usually GPs with a reduced workload in medical care ${ }^{4}$. Nursing staff is rarely represented in leadership positions. However, recent trends show that nurses are surfacing in leadership positions in rural areas ${ }^{11}$.

Usually, the primary health centres' opening hours are from 8 to 21 hours or from 7 to 20 hours and vary depending on whether they are in urban or rural areas. Primary care emergency services located in some health centres provide urgent care to ensure a 24 -hour service, seven days a week ${ }^{6}$.

The Spanish PHC encompasses acute and chronic care, health promotion and prevention activities, physiotherapy, mother and child care, mental health care, palliative care, medical counselling, and basic dental health services ${ }^{3,6}$. 
Table 2. Characteristics of the National Health System of Spain.

\begin{tabular}{|c|c|}
\hline Characteristics & Data \\
\hline Population with health coverage financed by public funds & $100.0 \%$ \\
\hline Predominant source of financing for public health expenditure & Taxes \\
\hline PHC with gatekeeping function to specialised care & yes \\
\hline Registration at a PHC centre & Mandatory \\
\hline Predominant mode of provision in primary and specialised care & Public \\
\hline Predominant organisation in primary care & Primary health care centres \\
\hline Predominant organisation in specialised ambulatory care & Hospital outpatient departments \\
\hline Portfolio of services defined at central level & yes \\
\hline Freedom of choice of doctors in primary care & yes \\
\hline Remuneration of doctors in primary care & Mix of salary and capitation \\
\hline Remuneration of doctors in outpatient specialised care and hospital & salary \\
\hline List of population per GP (Spain $)^{1}$ & 1,400 users \\
\hline List of population per GP $(\mathrm{CCAA})^{1}$ & $900-1,500$ users \\
\hline List of population per PHC nurse (Spain $)^{1}$ & 1,500 users \\
\hline List of population per PHC nurse $(\mathrm{CCAA})^{1}$ & $1,100-1,800$ users \\
\hline List of population $(0-14$ years $)$ per pediatrician $(\text { CCAA })^{1}$ & 800 to 1,100 children \\
\hline
\end{tabular}

Sources: Gobierno de Espanã ${ }^{29}$, Sanchez Fernandez ${ }^{26}$, elaborated by authors.

PHC centres in Spain are equipped for minor surgery; they also have equipment for diagnostic purposes such as spirometers, electrocardiogram machines, retinal digital cameras, and first aid material ${ }^{5}$. The multi-professional team can be augmented with paediatricians and paediatric nurses, physiotherapists, midwives, dentists, psychologists and social workers. The health professionals are supported by administrative staff and auxiliary nurses ${ }^{6}$.

Appointments can be made by phone, online or in person at the $\mathrm{PHC}$ centre. Additionally, patients have the choice to be seen by any of the health professionals in the PHC team where they are registered ${ }^{5}$. However, some PHC centres implemented a triage system in order to determine the urgency of the health problem of the patient and whether the patient should be consulted firstly by a GP or by a nurse ${ }^{11}$.

Other initiatives target improving access to primary care at the time needed, since it has been criticised in Spain that no more than $36 \%$ of patients requiring care get a consultation the same day $^{6}$. In Catalonia, a program for nurses providing same-day consultations for patients with minor illnesses at the PHC centres verifies the improvement of access to primary care ${ }^{30}$.

\section{Roles and tasks of nurses and interprofessional collaboration in $\mathrm{PHC}$}

The role of nurses in PHC has been mainly evolved around activities in the fields of health promotion, prevention, and chronic care. Nurses provide services during clinical appointments (scheduled or walk-in) in the health centres and at patients' homes for people mobility issues; additionally, they organise and conduct activities in group settings at the health centre, e.g. diabetes groups, and in the community, e.g. health promotion in schools ${ }^{24,31}$; however, the latter activities differ in scope and format across the $\mathrm{CCAA}^{31}$. In all these settings, the nurses take on responsibilities in the areas of diagnosis, therapeutics, health promotion, disease prevention, care, teaching and researching, which have been either delegated to them, or they have embraced autonomously ${ }^{32}$.

Nurses have gained increasing responsibilities in chronic care, acting as a key contact partners for the patients, ensuring regular examinations and providing continuous care and support for people with chronic diseases ${ }^{24,31,32}$. At the consultation, nurses usually conduct a comprehensive assessment, including the patient's social and health situation, lifestyle and health-related behaviour, health status and the promotion of self-management support. Furthermore, nurses are authorised and qualified to enjoin diagnostic procedures, such as blood tests or ultrasound examinations on their own ${ }^{5}$.

Today, the nurses play a vital role in chronic disease management of patients with diabetes and hypertension, and have critical roles in control and monitoring risk factors, as well as assessing the effect of treatments and medications ${ }^{33,34}$. 
They have a large degree of autonomy in the decision-making process and the care of patients ${ }^{5}$, but autonomy is different among CCAA.

In Spain, the teamwork of GPs and nurses and shared responsibility for patients is seen as a crucial point for high quality and continuing personal care. In most cases, one GP and one nurse work together for the same patient base $\mathrm{e}^{24}$. According to this concept of shared responsibility, GPs treat primarily the acutely ill and unstable chronic patients; nurses are responsible for chronic patients in stable conditions, besides health prevention and promotion ${ }^{32}$.

Collaboration between nurses and GPs intensifies with the complexity of the patient's needs since advanced therapy requires more detailed planning. For example, when dealing with immobile patients with complex health needs, joint visits at patient's home may be arranged ${ }^{5,24}$. If needed, other professionals in the teams may become involved, for example, social workers ${ }^{4}$. Hämel and Vössing ${ }^{24}$ conclude in a qualitative study that there is a strong commitment to teamwork by nurses and physicians in primary care teams.

This commitment has been encouraged in the Spanish PHC over the years by beneficial structures for team development. Current visions of the future are that doctors and nurses should integrate their competences to the point that they may provide care as equal partners. In this context, several PHC teams, aiming to improve patient care especially for the chronic patients, initiated new models of care division between doctors and nurses comprising advanced tasks and new roles for nurses in the teams ${ }^{24}$.

\section{Education of nurses and Advanced Practice Nursing (APN)}

To prepare nurses for advanced practice tasks and roles, appropriate study programs in nursing are needed, which help nurses to evolve their competences $^{12}$. The prerequisite for the today's role enhancement nurses in Spain was the introduction of nursing education as a 3-year study program at the university level in 1977 . To develop PHC, the programs established primary/ community health and gerontological nursing as mandatory undergraduate study courses for nurses ${ }^{32,35}$.

As part of the efforts to fulfil the criteria of the European Higher Education Area (EHEA) ${ }^{36}$, a common set of commitments to higher education in Europe, Spanish nursing education has evolved further in the last decade, from a 3-year diploma to a 4-year degree study program. The current program prepares nurses to achieve a high-competence level in clinical nursing, research and methodology ${ }^{31}$. Chiefly, master's degrees, nursing specialties, and doctoral programs have been introduced in the last decade. Since 2011, nurses have access to a 2-year governmental residency in a multi-professional teaching centre. They can specialise in seven areas (Table 3) ) $^{31,37,38}$. Respectively, Spanish nursing regulations designate two professional nursing categories: general and specialist nursing ${ }^{38}$.

Although the postgraduate nursing education courses has been established in Spain, this process is still at an early stage of development. Similarly, the APN has yet to be broadly adopted in Spain, and the available job positions are $\mathrm{few}^{33,38}$. As a result, roles and responsibilities of APN remain unclear in practice. Moreover, the adoption of the expanded nursing roles varies at CCAA.

The development of ANP in Spain lags behind that of other countries. The nurse practitioner role emerged in the USA in the mid 1960 ' $\mathrm{s}^{39}$. In the UK, nurse practitioners were introduced in the 1980s, and since the 1990s, accepted nurses' functions have increased in the English National Health Service, with the gradual transfer of functions previously carried out by doctors ${ }^{40}$. In a survey conducted in 2003, the International Council of Nurses identified over 60 countries developing advanced roles; however, the study also determined at the same time that job titles, educational preparations, role purpose and care settings vary greatly $y^{41}$.

APN is an umbrella term used to describe the expanded practice in a variety of nurses' roles. A variety of nomenclature is used globally ${ }^{42}$. The most important role definitions are cited in Table 4.

The main difference in the professional profile between advanced practice and general nurses is the capacity to take on more complex caseloads and manage them with greater independence, judgement, and accountability ${ }^{38}$. APNs should have higher educational qualifications than general nurses, for example, a master's degree in nursing or the completion of a nursing residency program (Table 3$)^{31}$. Recent studies ${ }^{43}$ confirm that the development model of the specialist nurse in Spain corresponds to the international development model of APN, among them the family and community nurse, specialised in $\mathrm{PHC}^{38}$. 
Table 3. Nursing Education in Spain.

\begin{tabular}{ll}
\hline Introduction of academic nursing education & 1977: first undergraduate nursing course \\
& 2006: first master program in nursing science \\
& 2006: first PhD program in nursing \\
\hline Required education for registered nurses & 1977: 3-year bachelor (former diploma) \\
& 2008/09: 4-year Bachelor \\
\hline Primary/community health care in nursing science curricula & 1990: Compulsory in the bachelor's curriculum \\
\hline Special training PHC nurses & 2005: legal base for 2-year residency \\
& 2011: initiation of 2-year residency program \\
\hline Nursing specialisations for general nurses in residency & . obstetric-gynaecological/midwifery \\
programs & . mental health \\
& . occupational/work related health \\
& .geriatrics \\
.primary/family and community \\
. medical-surgical nursing \\
.paediatric nursing
\end{tabular}

Table 4. Definitions of Advanced Practice Nursing.

\begin{tabular}{|c|c|}
\hline Institution & Definition \\
\hline $\begin{array}{l}\text { American Nurses } \\
\text { Association - } \\
\text { ANA }^{47}\end{array}$ & $\begin{array}{l}\text { "... is a regulatory title and includes the four roles" (Certified Registered Nurse } \\
\text { Anesthetists (CRNAs), Certified Nurse-Midwives (CNMs), Clinical Nurse Specialists } \\
\text { (CNSs), and Certified Nurse Practitioners (CNPs). "The core competencies for education } \\
\text { and the scope of practice are defined by the professional associations. State law and } \\
\text { regulation further define criteria for licensure for the designated scopes of practice. The } \\
\text { need to ensure healthcare consumer safety and access to APRNs by aligning education, } \\
\text { accreditation, licensure, and certification is shown in Consensus Model for APRN } \\
\text { Regulation: Licensure, Accreditation, Certification, and Education" }\end{array}$ \\
\hline $\begin{array}{l}\text { Canadian Nurses } \\
\text { Association - } \\
\text { CNA }^{48}\end{array}$ & $\begin{array}{l}\text { "Advanced practice nursing (APN) is an umbrella term for registered nurses (RNs) and } \\
\text { nurse practitioners (NPs) who integrate graduate nursing educational preparation with } \\
\text { in-depth, specialized clinical nursing knowledge and expertise in complex decision- } \\
\text { making to meet the health needs of individuals, families, groups, communities and } \\
\text { populations." }\end{array}$ \\
\hline $\begin{array}{l}\text { International } \\
\text { Council of Nurses } \\
-\mathrm{ICN}^{49}\end{array}$ & $\begin{array}{l}\text { "A Nurse Practitioner/Advanced Practice Nurse is a registered nurse who has acquired } \\
\text { the expert knowledge base, complex decision-making skills and clinical competencies for } \\
\text { expanded practice, the characteristics of which are shaped by the context and/or country } \\
\text { in which s/he is credentialed to practice. A master's degree is recommended for entry } \\
\text { level". }\end{array}$ \\
\hline $\begin{array}{l}\text { Understanding } \\
\text { of APN in Spain } \\
\text { according to } \\
\text { Comellas Oliva }^{31}\end{array}$ & $\begin{array}{l}\text { This kind of nurse "can concentrate on a specific area of knowledge patient-type by } \\
\text { undertaking postgraduate training, where they can develop specific clinical competences. } \\
\text { They form an extension of expert practice, thanks to the integration of theoretical } \\
\text { knowledge, practice, and the ability to individualise care"31 (p. 937). }\end{array}$ \\
\hline
\end{tabular}

The APN roles in Spain integrate research, education, practical experience and management with a high level of professional autonomy, evolving certain skills, such as advanced health assessment, decision-making, and diagnostic reasoning. In addition, the APN plans, implements and evaluates health programs. APN are known also to have advanced clinical competences and provide consultant services to other health workers ${ }^{50}$. 
tients' needs in complex chronic conditions. For example, in Basque Country the Nurse Continuity Manager and the Nurse Manager of Advanced Competences are responsible for developing care in chronic situations. In Andalusia, Catalonia, Valencia, Navarra, Madrid, Murcia and Aragon, the position of Case Manager Nurse was established to work both in the community and hospitals and help families in coping with complex health situations ${ }^{50}$. Due to the mentioned diversity in job descriptions and regulations, the expansion in nurses' roles has not led to a shared perception of APN throughout Spain, attesting to the difficulty of such developments of this area.

Furthermore, according to Sánchez-Gomez et al. ${ }^{50}$ and the APN requirements reviewed by the Spanish National Organisation of Nurse Practitioner Faculty for ANP in 2017 $7^{51}$, four competencies inherent to the definition of this role and responsibilities in PHC can be described in Table 5.

Another problem in Spain to APN roles is that the legal framework is insufficiently developed ${ }^{38}$, especially for nurses' prescription. In the last 15 years in Spain, nurses prescribing has faced many challenges and even backslides: "from not being a legal issue to implicit legality, explicit illegality" 4 . To date, physicians have controlled the prescription of drugs and health care material. However, in practice, due to protocols and informal verbal arrangements, nurses were used to prescribing in Spain. Local teams have developed their own procedures to enable nurses to prescribe medications, when necessary, by devising special protocols ${ }^{24}$.

Nevertheless, in July 2015, a Royal Decree (1/2015) reformulated previous prescription-related laws specifying that nurses could prescribe healthcare products and/or supplies related to nursing care, and medications not subject to medical prescription (while eligible for National Health Service coverage $)^{37}$. The decree required that professional organisations of doctors and nurses devise clinical guidelines and protocols for this practice, which then had to be validated by the Healthcare Ministry. Furthermore, it stipulated that a training course (6 ECTS) for nurse prescribing accreditation be required for both general and specialised nursing ${ }^{37,44}$.

In fact, this right to prescribe is quite limited due to the legislative framework, which broadens the required basic training and includes some restrictions, such as prohibiting nurses from prescribing prescription medication. Despite all hopes and efforts to promote it, the Royal Decree from October 2015 (954/2015) instead rejects prescriptions as a nursing competence and confirms established practice. It only grants nurses the competence of explaining or dispensing medicines, if they have been previously accred-

Table 5. Competences of the role and APN responsibilities in PHC in Spain.

\begin{tabular}{|c|c|}
\hline Competences & Responsibilities \\
\hline Advanced Clinic & $\begin{array}{l}\text { Patients' first contact by telephone assistance, emergencies or planned } \\
\text { appointments to minor and acute health problems, follow-up chronic patients. } \\
\text { These demands can be answered with health advice, specific indications or } \\
\text { drugs prescription. In addition, diagnostic tests, further process monitoring or } \\
\text { referral to other professionals could be applied. The APN can also interpret the } \\
\text { results and make clinical judgments, both autonomously and jointly with other } \\
\text { team members. The prescribing authority allows the APN to start a specific } \\
\text { treatment or renew a previous one within their specific group of patients. }\end{array}$ \\
\hline Management & $\begin{array}{l}\text { A procedure that allows the APN to refer to socio-health professionals, and vice } \\
\text { versa. }\end{array}$ \\
\hline Teaching & $\begin{array}{l}\text { An active participation in training programs for nursing students and registered } \\
\text { nurses. }\end{array}$ \\
\hline Research & $\begin{array}{l}\text { Evidence-based facilitator, elaborating evidence-based recommendations, } \\
\text { protocol development and clinical practice guidelines, as well as taking part in the } \\
\text { design of quality standards and indicators, also in patients' assessment and safety. }\end{array}$ \\
\hline $\begin{array}{l}\text { APN requirements in Spain } \\
\text { by the Spanish National } \\
\text { Organisation of Nurse } \\
\text { Practitioner Faculty }(2017)^{51}\end{array}$ & $\begin{array}{l}\text { APN should be performing tasks in nine areas of core competence: scientific } \\
\text { foundation, leadership, quality, practice inquiry, technology and information } \\
\text { literacy, policy, health delivery system, ethics, and independent practice. }\end{array}$ \\
\hline
\end{tabular}


ited $^{52}$. Such procedures are allowed, if the person prescribing has conducted a medical diagnosis. Simultaneously, it excludes the competence for explaining or dispensing medicines after issuing a nursing diagnosis, and thus, it cultivates further the differences between the CCAA ${ }^{31}$. Again, since the new regulations concerning nurse's prescription have yet to be clearly defined by all CCAA, they have yet to be implemented ${ }^{6}$.

Despite the ambiguous legal infrastructure, nurses in Spain regularly prescribe vaccines, antiseptics or antipyretics, supplies for diabetes care, incontinence, and wound care, which are based on clinic guidelines in PHC all related to the nursing care tasks ${ }^{6,53}$. In addition, nurse-prescribing protocols exist for treating minor acute diseases and conditions $\mathrm{s}^{30}$. It should be noted that despite the differences among CCAA new extended practice regarding prescribing rights for nurses has been regulated and accreditation for advanced practice has been published under the heading of continuous professional development ${ }^{37,38,52}$.

Contrary to the Spanish nursing prescribing experience, England has adopted expanded nursing activities in PHC with the legal permission to prescribe. Practice there shows that the resulting care is similar to the one adopted by doctors, and the same quality of consultation is maintained following chronic conditions ${ }^{40}$.

Finally, the available evaluations of APN in primary care - in the Spanish context and beyond ${ }^{15,50}$ - reveal that APN can contribute to the improvement of primary health care manifold, however, further improvement in regard to role clarification, implementation and regulation is still needed.

\section{Final considerations}

The possibility of building a 'next generation of nurses' that assume APN roles in PHC is being acknowledged increasingly in many countries - including Spain. Taking a closer look at the situation in Spain by focusing on the role development of PHC nurses and state of evolvement of APN in the context of the Spanish NHS. Our findings indicate:

- After introducing health centres in the mid1980s, PHC nursing as well as multi-professional, team-based care with well-defined structures and a strong commitment was promoted. With this foundation, PHC centres and the PHC workforce evolved with the capacity to respond continually to changing health needs and new social chal- lenges as well as to health system problems such as budget constraints.

In the last decade, - in concordance with developments in many other countries - innovations in PHC nursing have been introduced, especially involving the care of patients with chronic conditions. Moreover, improved access for people with minor health problems has been deemed a nursing issue. According to our analysis, a strong and well elaborated multi-professional concept of PHC has been beneficial for the further development of nurses' roles and also the progress made in developing APN in Spain. This solid structure facilitated the advancement of nursing competencies in daily routines. This was assisted in Spain by team commitment as well as high education standards for PHC nursing.

The further implementation of educational programs to prepare nurses in Spain for expanded roles can contribute to making PHC more effective and efficient. APN education in Spain is still in its early stages and there is presently only limited evidence available on just how it can contribute best to improve PHC. Although progress has been made toward creating a common framework for nursing education, the fact that the CCAA has yet to produce a well-defined and accepted framework for nomenclature, role definition and responsibilities of Advances Practice Nurses is problematic; as a result, role uncertainties in APN prevail.

Another barrier to APN in Spain evolving to its full potential is the rejected corresponding legislation. This is particularly vital in the case of nurse prescribing. Legislation has failed to provide the necessary conditions to safeguard nurse prescribing. In the meantime, several health centres and teams have developed their own strategies to explore possibilities of this kind of task shifting and regulate prescribing by nurses in bottom-up processes. The bottom-up initiatives, however, need to be strengthened with top-down support as is evident internationally that nurses can be as effective as doctors in treating certain diseases, even to the extent of prescribing less medication to achieve successful outcomes.

In summary, the nurses have expanded their roles and functions in the primary care in Spain and treat patients side by side with the doctors. However, advanced practice is not broadly adopted and needs to be improved to develop PHC quality further.

Our analysis has only provided an overview on the role development of PHC nurses in the Spanish NHS based on literature. As we have 
shown, further research which considers the specific construction of the NHS in Spain, the PHC model and, more specifically, role concepts and role development for PHC nursing as well as the state of art of nursing education and legislation for ANP as important context factors to reconstruct progress made as well as future prospects for further developing nursing roles are needed.

\section{Collaborations}

K Hämel worked in the conception and design; drafted the article and revised it critically; and approved the final version. BRGO Toso worked in the conception and design; drafted the article and revised it critically; and approved the final version. A Casanova worked in the design; drafted the article and approved the final version. $\mathrm{L}$ Giovanella worked in the conception and design; drafted the article and revised it critically; and approved the final version.

\section{Acknowledgements}

The authors thank Virginia Penrose for English language editing and proofreading. 


\section{References}

1. World Health Organization (WHO). Regional Office for Europe \& European Observatory on Health Care Systems (European Observatory). Spain: Health Care Systems in Transition [Internet]. Copenhagen: WHO Regional Office for Europe; 2000 [cited 2019 Apr 29]. Available from: http://www.who.int/iris/handle/10665/108352

2. Hart JT. Primary medical care in Spain. Br J Gen Pract 1990; 40(335):255-258.

3. Borkan J, Eaton CB, Novillo-Ortiz D, Rivero Corte $\mathrm{P}$, Jadad AR. Renewing primary care: lessons learned from the Spanish health care system. Health Aff (Millwood) 2010; 29(8):1432-1441.

4. Garcia-Armesto S, Begona Abadia-Taira M, Duran A, Hernandez-Quevedo C, Bernal-Delgado E. Spain: Health system review. Health Syst Transit 2010; 12(4):1295.

5. Dedeu T, Bolibar B, Gené J, Pareja C, Violan C. Spain. In: Kringos DS, Boerma WGW, Hutchinson A, Saltman RB, organizers. Building primary care in a changing Europe - Case studies. Copenhagen: WHO Regional Office for Europe; 2015. p. 253-264.

6. Bernal-Delgado E, García-Armesto S, Oliva J, Sánchez Martínez FI, Repullo JR, PeñaLongobardo LM, Ridao-López M, Hernández-Quevedo C. Spain: Health system review. Health Syst Transit 2018; 20(2):1-179.

7. Kringos D, Boerma W, Bourgueil Y, Cartier T, Dedeu T, Hasvold T, Hutchinson A, Lember M, Oleszczyk M, Rotar Pavlic D, Svab I, Tedeschi P, Wilm S, Wilson A, Windak A, Van der Zee J, Groenewegen P. The strength of primary care in Europe: an international comparative study. Br J Gen Pract 2013; 63(616):e742-750.

8. Kringos DS, Boerma WGW, Hutchinson A, Saltman RB. Building primary care in a changing Europe. Copenhagen: WHO Regional Office for Europe; 2015.

9. Giovanella L, Stegmüller, K. The financial crisis and health care systems in Europe: universal care under threat? Trends in health sector reforms in Germany, the United Kingdom and Spain. Cad Saude Publica 2014; 30(11):2263-2281.

10. Organisation for Economic Cooperation and Development, European Observatory on Health Systems and Policies (OECD, European Observatory). Spain: Country Health Profile 2017, State of Health in the EU. Paris, Brussels: OECD Publishing, European Observatory on Health Systems and Policies; 2017.

11. Hämel K, Vössing C. Gesundheitszentren in Spanien (Centros de Salud). Stuttgart: Robert Bosch Stiftung; 2018.

12. Bryar R, Kendall S, Mogotlane SM. Reforming primary health care: a nursing perspective. Geneva: International Council of Nurses; 2012.

13. Kendall S. Nursing Perspectives and Contribution to Primary Health Care. Geneva: International Council of Nurses; 2008.

14. Maier CB, Aiken LH. Task shifting from physicians to nurses in primary care in 39 countries: a crosscountry comparative study. Eur J Public Health 2016; 26(6):927-934.

15. Laurant M, van der Biezen M, Wijers N, Watananirun K, Kontopantelis E, van Vught AJ. Nurses as substitutes for doctors in primary care. Cochrane Database Syst Rev [serial on the Internet]. 2018 [cited 2019 Apr 29]; 7:1-111. Available from: https://doi.
org/10.1002/14651858.CD001271.pub3

16. Freire JM. La atención primaria de salud y los hospitales en el Sistema Nacional de Salud. In: Navarro Lopez V, organizer. El Estado de Bien Estar en España. Madrid: Tecnos; 2004. p. 239-291.

17. Pereira AMM, Lima LD, Machado CV, Freire JM. Descentralização e regionalização em saúde na Espanha: trajetórias, características e condicionantes. Saude Debate 2016; 39(n. esp.):11-27.

18. Maciá-Soler L, Moncho Vasallo J. Sistema nacional de salud español: características y análisis. eglobal 2007; 6(1):1-14.

19. Indicatores Clave Sistema Nacional de Salud (INCLASNS) [Internet Database]. [cited 2019 Apr 04]. Available from: http://inclasns.msssi.es/main.html

20. Statista. Human development index score of Spain in selected years from 1990 to 2017 [Internet Database]. [cited 2019 Apr 15]. Available from: https://www.statista.com/statistics/877134/human-development-index-of-spain/

21. OECD Data Spain [Internet Database]. [cited 2019 Apr 16]. Available from: http://data.oecd.org/spain. htm

22. Legido-Quigley H, Pajin L, Fanjul G, Urdaneta E, McKee M. Spain shows that a humane response to migrant health is possible in Europe. Lancet Public Health 2018; 3(8):e358.

23. Repullo-Labrador JR. La sostenibilidad de las prestaciones sanitarias públicas. In: Presno Linera MA, organizer. Crisis económica y atención a las personas $y$ grupos vulnerables [Internet]. Oviedo: Universidad de Oviedo; 2012. (Procuradora General del Principado de Asturias, Procura 2). [cited 2019 Apr 30]. Available from: https://presnolinera.files.wordpress. com/2013/09/crisis-econc3b3mica-y-atencic3b3n-a -las-personas-y-grupos-vulnerables.pdf

24. Hämel K, Vössing C. The collaboration of general practitioners and nurses in primary care: a comparative analysis of concepts and practices in Slovenia and Spain. Prim Health Care Res Dev 2017; 18(5):492-506.

25. Gorrotxategi Gorrotxategi P, García Vera C, Graffigna Lojendio A, Sánchez Pina C, Palomino-Urda N, Rodríguez Fernández-Oliva CRR, Villaizán Pérez C, Vincent ES, Vallejo MDC, Miembros de la Junta Directiva y de las asociaciones federadas de la EAPap. Situación de la Pediatría de Atención Primaria en España en 2018. Ref Pediat Aten Primaria 2018; 20(79):e89-e104.

26. Sánchez Fernández C, Espinosa FV, Sánchez Bayle M. Los años de la crisis en Atención Primaria. (2) Recorte en los recursos humanos [página na Internet]. Actasanitaria; 2019. [cited 2019 Apr 12]. Available from: https://www.actasanitaria.com/los-anos-de-la-crisis-en-atencion-primaria-2-recorte-en-los-recursos -humanos/

27. Jauregui ML, Silvestre C, Valdes P, Gaminde I. Qualitative Evaluation of the Implementation of an Integrated Care Delivery Model for Chronic Patients with Multi-Morbidity in the Basque Country. Int J Integr Care 2016; 16(3):9.

28. Ministry of Health Social Services and Equality (MoHSE). Annual Report on the National Health System of Spain 2016 - Summary. Madrid: MoHSE; 2017. 
29. Gobierno de Espanã. Ministerio de Sanidad, Servicios Socialies e Igualdad. NHS Statistical Portal of the Ministerio de Sanidad. Health care systems in the European Union countries. Health characteristics and indicators [Internet]. Gobierno de Espanã: MS; 2017. [cited 2019 Apr 16]. Available from: http://www.mscbs.gob. es/en/estadEstudios/sanidadDatos/home.htm

30. Fabrellas N, Vidal A, Amat G, Lejardi Y, del Puig Deulofeu M, Buendia C. Nurse management of 'same day' consultation for patients with minor illnesses: results of an extended programme in primary care in Catalonia. J Adv Nurs 2011; 67(8):1811-1816.

31. Comellas-Oliva M. Developing the Advanced Practice Nurse in Catalonia. Rev Bras Enferm 2016; 69(5):934938.

32. López CC. Primary health care in Spain and Catalonia: a nursing model perspective. Rev Esc Enferm USP 2011; 45(spe. 2):1722-1730.

33. Planas-Campmany C, Quinto L, Icart-Isern MT, Calvo EM, Ordi J. Nursing contribution to the achievement of prioritized objectives in primary health care: a cross-sectional study. Eur J Public Health 2016; 26(1):53-59.

34. Norful A, Martsolf G, de Jacq K, Poghosyan L. Utilization of Registered Nurses in Primary Care Teams: A Systematic Review. Int J Nurs Stud 2017; 74:15-23.

35. Mariscal Crespo MI, Merino Navarro D, Mena Navarro F, Macia Soler L, Zabalegui Yarnoz A, Camacho Bejarano R. Academic and Professional Development of Nursing in Spain: a Decade for Change. In: Soomro S, organizer. New Achievements in Technology Education and Development. Rijeka: InTech; 2010. p. 337-356.

36. European Commission, EACEA, Eurydice. The European Higher Education Area in 2015: Bologna Process Implementation Report [Internet]. Luxembourg: Publications Office of the European Union; 2015. [cited 2019 Apr 12]. Available from: https://doi. org/10.2797/128576

37. Spain. Real Decreto 1, de 24 de julio de 2015. Por el que se aprueba el texto refundido de la Ley de garantías y uso racional de los medicamentos y productos sanitarios. Boletín Oficial del Estado; 2015.

38. Sevilla Guerra S, Miranda Salmerón J, Zabalegui A. Profile of advanced nursing practice in Spain: A crosssectional study. Nurs Health Sci 2018; 20:99-106.

39. Delamaire M, Lafortune G. Nurses in Advanced Roles. A Description and Evaluation of Experiences in $12 \mathrm{De}$ veloped Countries. Paris: OECD; 2010. (OECD Health Working Papers No 54).

40. Toso BRGO, Filippon J, Giovanella L. Nurses' performance on primary care in the National Health Service in England. Rev Bras Enferm 2016; 69(1):169-177.

41. McDonnell A, Goodwin E, Kennedy FR, Hawley K, Gerrish K, Smith C. An evaluation of the implementation of Advanced Nurse Practioner (ANP) roles in an acute hospital setting. J Adv Nurs 2015; 71(4):789-799.

42. Kaldan G, Nordentoft SMJ, Herling SF, Larsen A, Thomsen T, Egerod I. Evidence characterizing skills, competencies, and policies in advanced nursing practice in intensive care in Europe: a scoping review protocol [Internet]. Plymouth: University of Plymouth; 2019. [cited 2019 Apr 30]. Available from: http://hdl.handle. net/10026.1/13287
43. Giménez Maroto AM. La enfermería y la práctica avanzada: Su desarrollo en España. Madrid, Spain: Universidad Complutense de Madrid; 2013.

44. Romero-Collado A, Raurell-Torreda M, Zabaleta-Del -Olmo E, Rascon-Hernan C, Homs-Romero E. Nurse prescribing in Spain: The law and the curriculum. Nurs Health Sci 2017; 19(3):373-380.

45. Spain. Real Decreto 450, de 22 de abril de 2005. Sobre especialidades de Enfermeria. Boletín Oficial del Estado; 2005.

46. Robinson S, Griffiths P. Nursing education and regulation: international profiles and perspectives. London: National Nursing Research Unit; 2007.

47. American Nurse Association (ANA). Nursing: Scope and standards of practice [Internet]. Washington DC: ANA; 2010. [cited 2015 Jul 21]. Available from: https://www.speakcdn.com/assets/2369/nursingscopestandards.pdf

48. Canadian Nurses Association (CNA). Advanced nursing practice. A National Framework [Internet]. Ottawa: Canadian Nurse Association; 2019. [cited 2015 Jul 21]. Available from: https://www.cna-aiic.ca/-/ media/cna/page-content/pdf-en/advanced-practicenursing-framework-en.pdf?la $=$ en $\&$ hash $=76$ A98ADEE62E655E158026DEB45326C8C9528B1B

49. International Council of Nurses Nurse Practitioner/ Advanced Practice Nursing Network (ICN). Definition and Characteristics of the Role [Internet]. [cited 2019 Apr 29]. Available from: http://international. aanp.org/practice/apnroles

50. Sánchez-Gómez MB, Ramos-Santana S, Gómez-Salgado J, Sánchez-Nicolás F, Moreno-Garriga C, Duarte-Clíments G. Benefits of Advanced Practice Nursing for Its Expansion in the Spanish Context. Int J Environ Res Public Health 2019; 16(5):680.

51. National Organization of Nurse Practitioner Faculty (NONPF). Nurse Practitioner Core Competences Content [Internet]. 2017 [cited 2019 Jan 3] Available from: https://cdn.ymaws.com/www.nonpf.org/resource/ resmgr/competencies/2017_NPCoreComps_with_ Curric.pdf

52. Spain. Real Decreto 954, de 23 de octubre de 2015. Por el que se regula la indicación, uso y autorización de dispensación de medicamentos y productos sanitarios de uso humano por parte de los enfermeros. Boletín Oficial del Estado; 2015.

53. Romero-Collado A, Homs-Romero E, Zabaleta-del -Olmo E, Juvinya-Canal D. Nurse prescribing in primary care in Spain: legal framework, historical characteristics and relationship to perceived professional identity. J Nurs Manag 2014; 22(3):394-404.

Artigo apresentado em 13/04/2019

Aprovado em 20/08/2019

Versão final apresentada em 27/09/2019 